Revista de la red interuniversitaria de estudios sobre las literaturas rioplatenses contemporáneas en Francia

$11 \mid 2014$

De niños e infancias

\title{
De niños e infancias
}

\section{Gersende Camenen y Victoria Liendo}

\section{OpenEdition}

Journals

\section{Edición electrónica}

URL: http://journals.openedition.org/lirico/1786

DOI: $10.4000 /$ lirico. 1786

ISSN: 2262-8339

Editor

Réseau interuniversitaire d'étude des littératures contemporaines du Río de la Plata

\section{Referencia electrónica}

Gersende Camenen y Victoria Liendo, «De niños e infancias », Cuadernos LIRICO [En línea], 11 | 2014,

Publicado el 01 diciembre 2014, consultado el 22 septiembre 2020. URL : http://

journals.openedition.org/lirico/1786; DOI : https://doi.org/10.4000/lirico.1786

Este documento fue generado automáticamente el 22 septiembre 2020

\section{(c) (i) (9)}

Cuadernos LIRICO está distribuido bajo una Licencia Creative Commons Atribución-NoComercialSinDerivar 4.0 Internacional. 


\title{
De niños e infancias
}

\author{
Gersende Camenen y Victoria Liendo
}

1 A Sarmiento, el niño sabio, lo llevan de casa en casa como al prodigio del pueblo para oírlo leer en voz alta. Norah Lange, la niña excéntrica, grita desaforada en distintos idiomas y finge carcajadas enloquecidas desde el techo de su casa hasta gastar la voz. Reinaldo Arenas, el niño salvaje, escribe, como Celestino, poemas con un cuchillo en el tronco los árboles para que no amanezca. Borges, el traductor precoz, lee a los seis años el Quijote en inglés sin tener la menor sospecha de que el original fue escrito en español. Fernando Vallejo, el niño furioso, se golpea la frente contra las baldosas del patio para desconcierto de la criada. Felisberto Hernández, el niño melancólico, cuando está solo se hace amigo de las sillas y les levanta la pollera. Victoria Ocampo, la actriz doméstica, declama versos de Racine con la secreta convicción de estar contando con ellos sus angustias del día. Silvio Astier y su pandilla de barrio asaltan la biblioteca municipal y rescatan Las Flores del Mal del iletrado saqueo. Podría escribirse una historia de las infancias literarias o una historia de la literatura desde la infancia. ¿Pero qué quiere decir pensar la literatura desde la infancia? Este número se propone plantear una serie de interrogantes y construir posibles respuestas para reflexionar sobre el cruce entre literatura e infancia.

De los diferentes artículos aquí presentados surge con insistencia una misma idea : si bien la infancia participa de una compleja intimidad con nociones como el origen y la verdad, ya no encontramos una visión teleológica del tiempo que la ordene, que le asigne el unívoco lugar del comienzo y le otorgue un estatuto de causa en el devenir del sujeto. Julio Premat, a partir de una reflexión sobre los relatos autobiográficos, distingue dos maneras de explorar la infancia: desde la vejez, con la tonalidad del testamento o, al contrario, desde el presente, como la fundación de un proyecto o de una estética. La infancia se convierte así en un laboratorio de escritura. Es el caso de Felisberto Hernández, Norah Lange y Fernando Vallejo quienes no buscan en sus primeros años un pasado que explicaría lo ya escrito sino que retoman "el origen y sus valores simbólicos para empezar de nuevo y fundar una obra literaria aparte". De este modo, la infancia define una actitud frente a la escritura: la decisión de mirar hacia atrás o hacia delante. 
Se cuestiona también otro topos, aquel que fija a la infancia como un lugar aislado en el tiempo y en el espacio, un lugar de inocencia, felicidad y pureza que permanece a salvo de la sociedad. José Amícola hace un estudio comparativo de Silvina Ocampo y Marosa di Giorgio en el cual analiza a la infancia como un paisaje permeable a conflictos sociales y de género. El "pan-sexualismo sin maldad" de la poeta uruguaya se opone radicalmente al mundo de veredas y escaleras de las crueles niñas ocampianas. Amícola hace uso de una distinción entre superficies lisas y superficies estriadas (Deleuze y Guattari) para contrastar el paisaje marosiano, esa "estepa apta para el nomadismo, para ser surcada en todas direcciones al azar" contra los "espacios estriados por la costumbre y los hábitos de clase" de Cornelia y su espejo. Julien Roger, por su parte, también cuestiona la idea de la infancia como vert paradis en Cuadernos de infancia (1937) y Viaje olvidado (1937). Para el investigador francés, la infancia que representan ambas escritoras es una época marcada por experiencias dolorosas y traumáticas. Mediante un análisis narratológico de la organización temporal, el trabajo poético y la focalización, Roger muestra que los textos logran resolver la crisis que relatan. La infancia ilustra aquí la primacía de la literatura sobre la vida.

4 La infancia es también una forma privilegiada para trabajar la memoria íntima y colectiva. Dos artículos interrogan la figura del niño como síntoma de eventos traumáticos que no tienen representación en el texto. Alejandra Josiowicz propone una lectura de la muerte del hijo en La vida de Dominguito de Sarmiento a partir de una reflexión sobre la escritura del duelo. Muestra que al interrumpir la genealogía, la muerte del hijo revela la fragilidad de todo destino, propio y familiar, pero también del porvenir de la nación. Así, para Josiowicz, la muerte del hijo funciona como "síntoma de la dificultad de Sarmiento para concebir un legado político para la Argentina futura". Pero el trabajo de duelo, que en La vida de Dominguito se elabora a partir del encuentro poético entre las primeras y las últimas palabras del niño difunto, refunda la subjetividad de Sarmiento al provocar en él un "verdadero despertar" ético del padre, testigo y sobreviviente de una infancia fantasma. María José Punte, por su lado, se interroga sobre el uso frecuente de una mirada infantil en la narrativa reciente sobre la memoria colectiva. Muestra que la percepción infantil confiere un nuevo sentido a los espacios privados y públicos y permite recuperar una forma de intensidad de la experiencia. De esta manera los niños se vuelven testigos y actores originales de la historia : su presencia ofrece hoy la posibilidad del "retorno a un nuevo comienzo" que abre la reflexión sobre el devenir colectivo en vez de cerrarla sobre una simple representación del pasado.

5 Por otra parte, la infancia puede ser también pensada como lo que está afuera del tiempo, un más allá o un más acá del tiempo funcionando como experiencia y experimento epistemológicos. La infancia sería aquí el instante pleno, el presente puro o la perfecta sincronía donde se produce una abstracción del flujo temporal, de la historia y del lenguaje. En el marco de estas reflexiones, Hebert Benítez Pezzolano analiza cómo la reconfiguración poética del mundo de infancia en Los papeles Salvajes de Marosa di Giogio posee un sentido crítico sobre las limitaciones del tiempo y las estructuras poético-narrativas que buscan darles expresión. Surge así lo "inenarrable", consecuencia de la inefabilidad de la experiencia de retorno. Frente a las limitaciones del lenguaje, se configura un mundo autónomo con una temporalidad otra, un espacio y un tiempo fundados en la infancia pero que, a su vez, la exceden. Así, el ayer de la 
infancia irrumpe como tiempo efectivo del ahora en una coexistencia de la voz infantil y la voz adulta que impide la linealidad para que no se borre el tiempo primordial.

Por último, la figura del niño o la infancia como noción pueden también funcionar como un dispositivo teórico o un objeto de pensamiento. Para Daniel Link, la infancia es un estado de la imaginación con una lógica propia, lógica de lo imaginario, de la ausencia, la fuga y el rapto. Evocarla es convocar esa falta antes que asociarla a niños o a una época dorada ; es la carencia de un lugar antes que un lugar. A través de la teoría de Agamben, Link nos propone pensar en la infancia del hombre, es decir, en el origen de la experiencia y de la historia, en el acontecimiento. Desde esta perspectiva, rescata de entre las lecturas de Pizarnik una cita subrayada de un texto de Michaux que interroga la posibilidad de actuar sobre la vida prenatal del hombre. Asimismo, analiza cómo en la poeta argentina, en Arturo Carrera y en Osvaldo Lamborghini aparece "esa infancia que es, al mismo tiempo, la propia y la infancia de la humanidad, perdida y olvidada en la catástrofe de una Historia congelada para siempre." El poema, de este modo, coexiste con una voz primitiva : en él se escuchan simultáneamente "la voz de la infancia de la humanidad y la del individuo". En este artículo, Daniel Link investiga en la infancia no solamente "lo previo al lenguaje" sino "la pre-historia de la humanidad, cuando no había teatrillos del yo y el arte se limitaba al rumor de los insectos, las bandadas de pájaros, la canción de la tierra." En sintonía con esta perspectiva de análisis, a partir de ciertos postulados de la arqueología filosófica, Valentín Díaz observa que el concepto de origen no es obsoleto si lo concebimos como algo que persiste en el presente. La imagen del Big Bang le permite, siguiendo a Sarduy y a Agamben, pensar esa persistencia: "el origen es luz y sonido que, productos del estallido primero, siguen llegando a nosotros". Rastreando a la infancia como una experiencia de lo originario, Díaz propone una lectura de dos novelas argentinas recientes (La sucesión de Cynthia Edul y El amor nos destrozará de Diego Erlan) donde la experiencia como vaciamiento y la infancia como pobreza permiten la restitución del aura, "un acceso al Origen de los tiempos".

7 Para cerrar el número, queremos prolongar la reflexión sobre la infancia con un conjunto de textos literarios inéditos ${ }^{1}$ de escritores y poetas argentinos contemporáneos. El más entusiasta de los agradecimientos a ellos que le dan vida a la discusión teórica y nos invitan a leer infancias de hoy.

\section{NOTAS}

1. Los textos narrativos son en su mayoría inéditos, a excepción del de Hernán Ronsino y el de Pedro Mairal, que fue publicado de forma online salvo el fragmento "El conejo" que aparece por primera vez en este número. 